\title{
Composite Right/Left-Handed Transmission-Line Based Wideband Antenna for WLAN, WiMAX and WiFi Applications
}

\author{
Mohammad Alibakhshi-Kenari ${ }^{1}$, Mohammad Naser-Moghadasi ${ }^{1}$, Ramazan Ali Sadeghzadeh ${ }^{2}$, Bal Singh Virdee ${ }^{3}$ and Ernesto \\ Limiti $^{4}$ \\ ${ }^{1}$ Faculty of Eng., Science and Research Branch, Islamic Azad University, Tehran, Iran \\ ${ }^{2}$ Faculty of Electrical Eng., K N University of Technology, Tehran, Iran \\ ${ }^{3}$ London Metropolitan University, Center for Communications Technology, London N7 8DB, UK \\ ${ }^{4}$ Dipartimento di Ingegneria Elettronica, Università degli Studidi Roma TorVergata,Via del Politecnico 1, 00133 Roma, Italy
}

\begin{abstract}
In this article, a new and compact wideband antenna is presented based on metamaterial composite right/left-handed transmission-line (CRLH-TL) structures. The proposed wideband planar antenna provides enhanced gain performance and is optimized for bandwidth, efficiency and radiation patterns. The CRLH-TL is realized by embedding two inverted F-shaped slots inside a rectangular radiation patch which is inductively grounded through a metal via-hole. The antenna is constructed using two CRLH-TL unit-cells to cover the frequency span from $3.1 \mathrm{GHz}$ to $5.4 \mathrm{GHz}$, which corresponds to a fractional bandwidth of $54.11 \%$. The overall size of the antenna is $11 \mathrm{~mm} \times 7.4 \mathrm{~mm} \times 0.8 \mathrm{~mm}$ or $0.15 \lambda_{0} \times 0.1 \lambda_{0} \times 0.011 \lambda_{0}$, where $\lambda_{0}$ is free space wavelength at the operating frequency of 4.25 GHz. The antenna has a maximum gain and radiation efficiency of $6.4 \mathrm{dBi}$ and $89.04 \%$, respectively, at $5.4 \mathrm{GHz}$. The proposed antenna finds application in various wireless technologies including WLAN, WiMAX and WiFi.
\end{abstract}

Index Terms - Small antenna, composite right/left-handed transmission line (CRLH-TL), wideband antenna, wireless communication systems, F-shaped slots.

\section{INTRODUCTION}

In recent years modern wireless communications systems are required to increasingly handle higher and higher data transmission rates using antennas with a small foot print. Hence there is currently a strong demand for antennas that have the following qualities: (i) small size; (ii) having wideband characteristics; (iii) can be easily integrated in portable wireless communications systems; and (iv) is lowcost [1-3]. These requirements are now becoming possible with the advent of UWB technology. In particular, implementation of such antennas using printed circuit boards is attractive as it offers advantages of compactness, planar profile, low-cost, light weight and broadband features. Furthermore, these antennas are compatible with microwave integrated technology that eases integration in RF systems.

Over recent years composite right/left-handed transmission lines (CRLH-TLs) have drawn broad interest and have led to utilization in many electromagnetic applications from the microwave to optical regime, especially for the radiated-wave devices. CRLH-TLs are manmade composite materials, engineered to produce electromagnetic propagation behavior not found in natural media [4-5]. These unusual properties have been used to improve the performance of microwave devices including antennas. Although microstrip antennas with wideband performance have been developed for application in modern wireless communications systems [6-7], however the size of these antennas is considered to be unsatisfactory to enable system miniaturization. Several techniques have been investigated to reduce the size of such antennas [8]; however such techniques result in increased design complexity that is expensive to implement. To overcome this deficiency antenna realized using CRLH-TL is yielding promising results [9-18]. Various implementations of CRLH-TLs structures have been reported and demonstrated [19-23].

In this paper, we have used the CRLH-TL technology to achieve a wideband antenna with a small foot print area and with enhanced gain performance. The proposed antenna consists of two unit-cells implemented with two inverted Fshaped slots etched in a rectangular patch which is inductively grounded through a spiral. The F-shaped slots create series capacitances $\left(C_{L}\right)$, and the inductive stub which is grounded through a metallic via-hole creates shunt inductance $\left(L_{L}\right)$. Unwanted right-handed parasitic effects associated with the unit-cells generate right-handed capacitance $\left(C_{R}\right)$ and inductance $\left(L_{R}\right)$ that need to be considered in the antenna analysis. The proposed structure exhibits the required wide bandwidth and miniaturization along with enhanced radiation properties such as gain and efficiency. These features make the proposed antenna applicable in UWB systems.

\section{DESIGN OF THE WIDEBAND PROTOTYPE ANTENNA}

The CRLH-TL unit-cells can be implemented using either surface mount chip components and/or distributed transmission-lines as discussed in [11-23]. Lumped components are not preferred in antenna designs because they 
are lossy and have limited discrete values. Here we have used printed circuit board techniques to implement the proposed antenna structure as it has advantages of reduced foot print area, low-loss and low-profile.

The proposed antenna, which is based on two CRLH-TL unit-cells, has wideband characteristics and is miniature in size. The unit-cell is composed of two inverted F-shaped slots that are facing each other and are in close proximity. The unit-cell is etched inside a rectangular patch which is grounded through an inductive stub, as shown in Fig. 1. The equivalent circuit model of the antenna is shown in Fig. 2, where the series capacitances $\left(C_{L}\right)$ represent the F-shaped slots, and the shunt inductance $\left(L_{L}\right)$ represents the inductive stub which is grounded through a metallic via-hole. The parasitic effects associated with the unit-cells are represented by the right-handed capacitance $\left(C_{R}\right)$ and inductance $\left(L_{R}\right)$. In this structure, port-1 is excited with the input signal and port2 is matched to $20 \mathrm{Ohm}$ load impedance, which is an SMD component. Because the lowest mode of operation is a lefthanded mode, the propagation constant, which approaches negative infinity at the cutoff frequency, reduces in magnitude as the frequency increases. This phenomenon makes the antenna physically small but is electrically large.

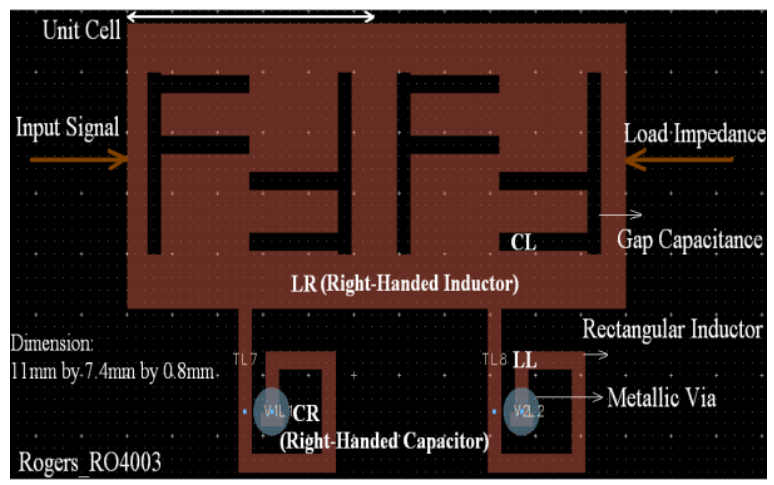

(a)

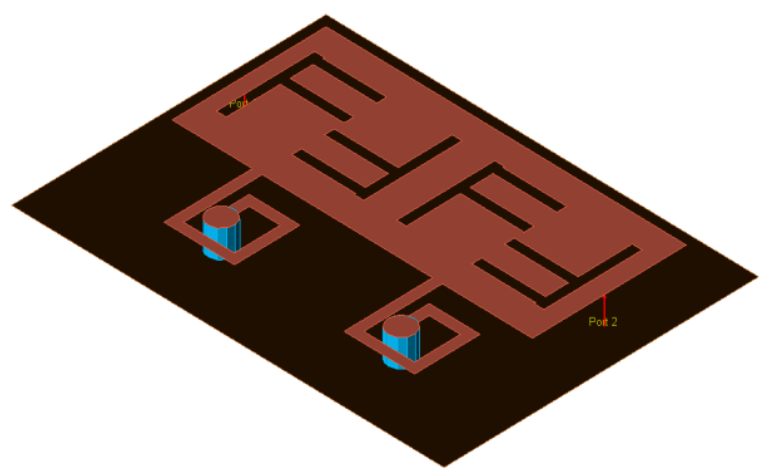

(b)

Fig.1. Configuration of the proposed UWB antenna composed of the two unit-cells based on CRLH-TL, (a) Top view, and (b) Isometric view.

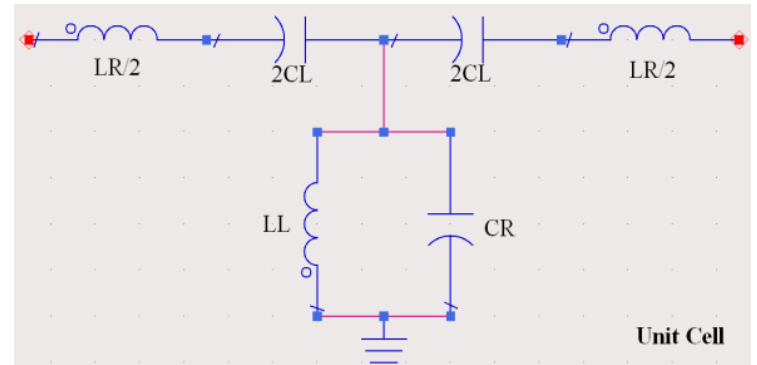

(a)

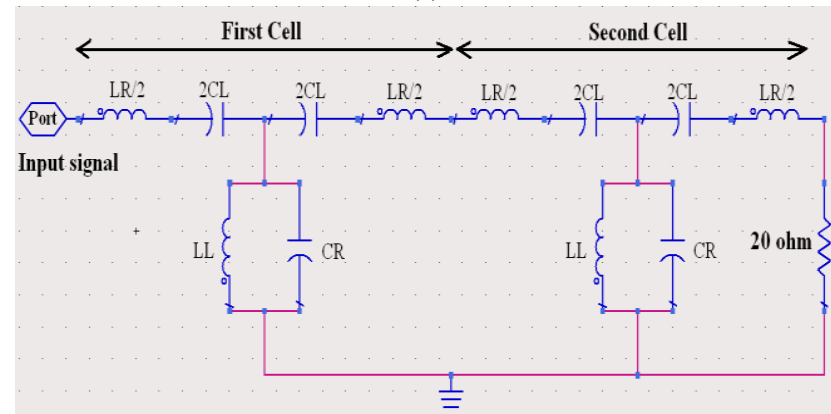

(b)

Fig.2. Equivalent circuit model of the proposed CRLH-TL antenna, (a) unitcell, and (b) overall structure.

\section{RESULTS AND DISCUSSIONS}

We have used CRLH-TL technology and printed circuit planar approach to realize a wideband antenna with a small foot print area. The total size of the antenna is $0.15 \lambda_{0} \times 0.1 \lambda_{0} \times 0.011 \lambda_{0}$, in terms of the free space wavelength $\left(\lambda_{0}\right)$ with an operating frequency of $4.25 \mathrm{GHz}$. The CRLH-TL based antenna was designed on a Rogers RO4003 substrate with dielectric constant of 3.38 , thickness of $0.8 \mathrm{~mm}$ and Tan $\delta$ of 0.0022 . The gap between the F-shaped slots was optimized to realize an impedance bandwidth of $2.3 \mathrm{GHz}$ extending from $3.1 \mathrm{GHz}$ to $5.4 \mathrm{GHz}$, which corresponding a fractional bandwidth of $54.11 \%$. The antenna was analyzed using Advanced Design System (ADS) full-wave electromagnetic simulator. Fig. 3 shows the reflection coefficient response of the antenna, where the bandwidth is defined for $S_{11} \leq-10 \mathrm{~dB}$. The radiation characteristics were improved by optimizing the structural parameters of the antenna including the number of spiral turns $(n)$, spiral inner radius $(R i)$, spiral width $(W s)$ and spacing between spiral turns $(S s)$, width of the metallic via-holes the good radiation performances have been achieved. Gain and efficiency of the proposed antenna varied from $-1 \mathrm{dBi}$ to $6.4 \mathrm{dBi}$ and from $15.25 \%$ to $89.04 \%$, respectively, over the frequency span 3.1 $\mathrm{GHz}$ to $5.4 \mathrm{GHz}$.

The antenna radiation gain patterns have plotted in Fig.4. As is clear, the radiation patterns have the unidirectional characteristics. The characteristics of the proposed antenna 
are compared with some other CRLH-TL based antennas in Table I. It is evident from this table compared to antennas reported in [26] and [27] the two unit-cells CRLH-TL antenna has a significantly higher gain of $6.4 \mathrm{dBi}$, a much wider bandwidth of $2.3 \mathrm{GHz}$ from $3.1 \mathrm{GHz}$ to $5.4 \mathrm{GHz}$, and much higher radiation efficiency of $89.04 \%$. The CRLH basedantenna has benefits of small dimensions, wide operational bandwidth, and has a high gain and high efficiency. These features make it suitable to support today's multiband wireless systems as well as emerging applications [24-25].

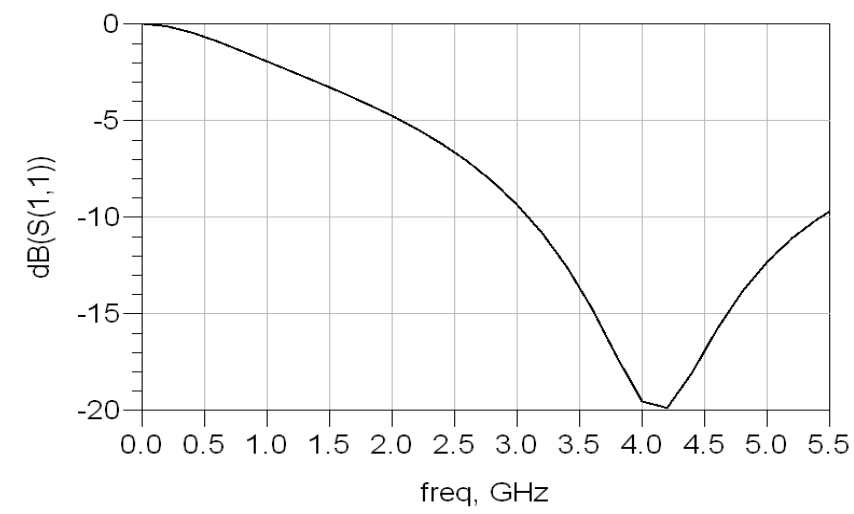

Fig.3. Reflection coefficient of the proposed antenna.

Table I. Comparison of dimensions and radiation characteristics of the proposed antenna with other CRLH-TL antennas.

\begin{tabular}{|l|c|c|c|}
\hline Parameters & {$[\mathbf{2 6}]$} & {$[\mathbf{2 7}]$} & Proposed Antenna \\
\hline Gain $(\mathbf{d B i})$ & 0.45 & 0.6 & 6.4 \\
\hline Bandwidth $(\mathbf{G H z})$ & $0.8-2.5$ & $1-2$ & $3.1-5.4$ \\
\hline Efficiency (\%) & 53.6 & 26 & 89.04 \\
\hline Dimensions & $\mathbf{0 . 4} \lambda_{0} \times \mathbf{0 . 0 3} \lambda_{0} \times \mathbf{0 . 0 3} \lambda_{0}$ & $\mathbf{0 . 0 7 \lambda _ { 0 } \times \mathbf { 0 . 0 7 } \lambda _ { 0 } \times \mathbf { 0 . 0 3 } \lambda _ { 0 }}$ & $\mathbf{0 . 1 5 \lambda _ { 0 } \times \mathbf { 0 . 1 } \lambda _ { 0 } \times \mathbf { 0 . 0 1 1 } \lambda _ { o }}$ \\
\hline
\end{tabular}

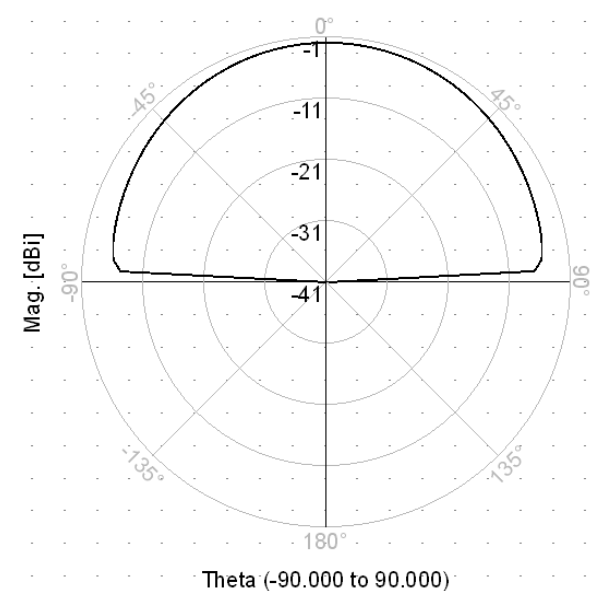

(a)

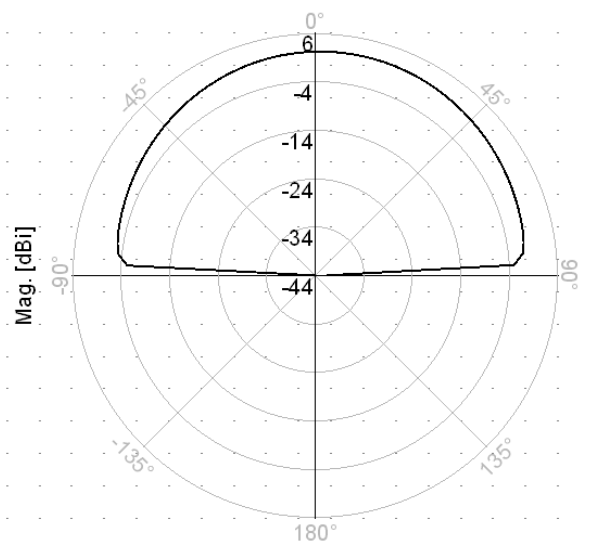

Theta $(-90.000$ to 90.000$)$

(b)

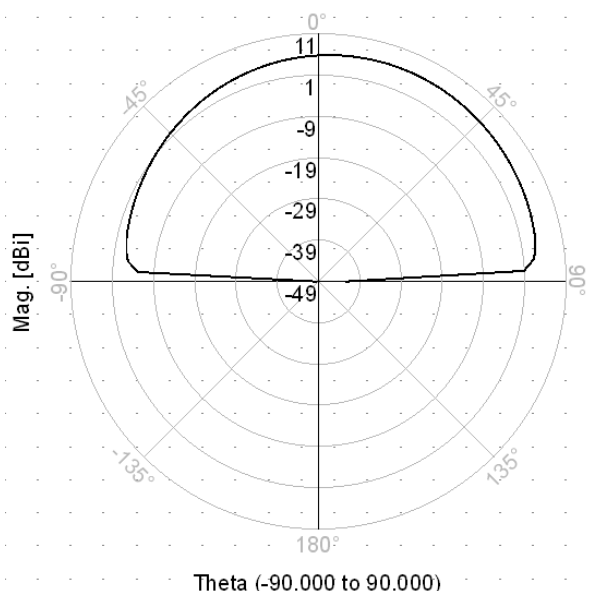

(c)

Fig.4. Radiation gain patterns of the proposed antenna in elevation plane ( $\Phi=0^{\circ}$ degree), (a) $3.1 \mathrm{GHz}$, (b) $4.25 \mathrm{GHz}$, and (c) $5.4 \mathrm{GHz}$.

\section{CONCLUSIONS}

A new wideband antenna is presented in this paper that has a small foot print and excellent gain and radiation performance. The antenna design is based on CRLH-TL unit-cells realized using two inverted $\mathrm{F}$-shaped slots embedded inside a radiation patch which is terminated to ground with an inductive stub in the shape of a spiral. The overall size of the antenna is $11 \times$ $7.4 \times 0.8 \mathrm{~mm}^{3}$ or $0.15 \lambda_{0} \times 0.1 \lambda_{0} \times 0.011 \lambda_{0}$. It has an impedance bandwidth of $2.3 \mathrm{GHz}$ from $3.1-5.4 \mathrm{GHz}$, which corresponding to a fractional bandwidth of $54.11 \%$. The antenna has a peak gain of $6.4 \mathrm{dBi}$ and maximum radiation efficiency of $89.04 \%$ at $5.4 \mathrm{GHz}$. These features make the antenna suitable for wireless communication systems such as WLAN, WiMAX and WiFi. 


\section{ACKNOWLEDGEMENT}

The authors would like to give special thanks to faculty of Microelectronics.

\section{REFERENCES}

[1] C. J. Lee, K. M. H. Leong, and T. Itoh, "Broadband Small Antenna for Portable Wireless Application," Proc. International Workshop on Antenna Technology: Small Antennas and Novel Metamaterials, pp. 10- 13, 2008.

[2] Mohammad Alibakhshi-Kenari, Aurora Andújar and Jaume Anguera, "New Compact Printed Leaky-Wave Antenna with Beam Steering," Microwave and Optical Technology Letters, Volume 58, Issue 1, January 2016, pp. 215-217.

[3] Mohammad Alibakhshi-Kenari, Mohammad Naser-Moghadasi, Ramazan Ali Sadeghzadeh and Bal Singh Virdee, "Hexa-Band Planar Antenna with Asymmetric Fork-Shaped Radiators for Multiband and Broadband Communication Applications," IET Microwaves, Antennas \& Propagation. DOI: 10.1049/iet-map.2015.0608, Available online: 21 March 2016.

[4] C. Caloz and T. Itoh, Electromagnetic Metamaterials: Transmission Line Theory and Microwave Applications, The Engineering Approach, New York, John Wiley \& Sons, 2005.

[5] R. A. Shelby, D. R. Smith, and S. Schultz, "Experimental Verification of a Negative Index of Refraction," Science,292, 55 14, 2001, pp. 77-79.

[6] W. L. Stutzman, Antenna Theory and Design, Second Edition: J. Wiley \& Sons, 1997.

[7] A. Sankarasubramaniam, "Design Guidelines for Tunable Coplanar and Microstrip Patch Antennas," Microwave Conference, European, 2007.

[8] K. L. Wong, Planar Antennas for Wireless Communications, WileyInterscience, 2003.

[9] A. Alù, "Subwavelength, Compact, Resonant Patch Antennas Loaded with Metamaterials," IEEE Transaction on Antennas and Propagation, vol. 55 , no. 1,2007

[10] Ourir, A, "Phase-varying metamaterial for compact steerable directive antenna," Electronics Letters, vol.43, pp. 493-494, 2007.

[11] R. A. Sadeghzadeh, M. Alibakhshi-Kenari and M. Naser-Moghadasi, "UWB Antenna Based on SCRLH-TLs for Portable Wireless Devices," Microwave and Optical Technology Letters, Volume 58, Issue 1, January 2016, pp. 69-71.

[12] Mohammad Alibakhshi-Kenari, Mohammad Naser-Moghadasi, Ramazan Ali Sadeghzadeh and Bal Singh Virdee, "MetamaterialBased Antennas for Integration in UWB Transceivers and Portable Microwave Handsets," International Journal of RF and Microwave Computer-Aided Engineering, Volume 26, Issue 1, January 2016, pages: 88-96.

[13] Mohammad Alibakhshi-Kenari, Mohammad Naser-Moghadasi, R. A. Sadeghzadeh, Bal Singh Virdee and Ernesto Limiti, "Dual-Band RFID Tag Antenna Based on the Hilbert-Curve Fractal for HF and UHF Applications," IET Circuits, Devices \& Systems, Volume 10, Issue 2, March 2016, pp. 140 - 146.

[14] M. Alibakhshi-Kenari, M. Naser-Moghadasi, B. S.Virdee, A. Andujar and J. Anguera, "Compact Antenna based on a Composite Right/Left Handed Transmission Line," Microwave and Optical Technology Letters, Volume 57, Issue 8, pp. 1785-1788, August 2015.

[15] Mohammad Alibakhshi-Kenari, "Introducing the new wideband small plate antennas with engraved voids to form new geometries based on CRLH MTM-TLs for wireless applications," International Journal of Microwave and Wireless Technologies, Volume 6, Special Issue 06 , December 2014, pp $629-637$.

[16] Mohammad Alibakhshi-Kenari, "Printed planar patch antennas based on metamaterial," International Journal of Electronics Letters, Volume 2, Issue 1, Jan 2014, pp 37-42.

[17] Mohammad Alibakhshi Kenari, "Design and Modeling of New UWB Metamaterial Planar Cavity Antennas with Shrinking of the Physical
Size for Modern Transceivers," International Journal of Antennas and Propagation, vol. 2013, Article ID 562538, 12 pages, 2013. doi:10.1155/2013/562538.

[18] Mohammad Alibakhshi-Kenari, Masoud Movahhedi and Ahmad Hakimi, "Compact and Ultra Wide Band Planar Antenna Based on the CompositeRight/Left-Handed Transmission Line Accompanying Improvement," First Iranian Conference on Electromagnetic Engineering (ICEME 2012), Tehran, Iran, December 2012.

[19] Mohammad Alibakhshi-Kenari, Mohammad Naser-Moghadasi and Ramazan Ali Sadeghzadeh "Composite Right-Left Handed BasedAntenna with Wide Applications in Very-High Frequency Ultra-High Frequency Bands for Radio Transceivers" IET Microwaves, Antennas \& Propagation, Volume 9, Issue 15, 10 December 2015, pp. 17131726.

[20] Mohammad Alibakhshi-Kenari, Mohammad Naser-Moghadasi, Ramazan Ali Sadeghzadah, "Bandwidth and Radiation Specifications Enhancement of Monopole Antennas Loaded with Split Ring Resonators" IET Microwaves, Antennas \& Propagation, Volume 9, Issue 14, 19 November 2015, pp. 1487 - 1496.

[21] Mohammad Alibakhshi-Kenari, Mohammad Naser-Moghadasi and Ramazan Ali Sadeghzadah, "The Resonating MTM Based Miniaturized Antennas for Wide-band RF-Microwave Systems,' Microwave and Optical Technology Letters, Volume 57, Issue 10, pp. 2339-2344, October 2015.

[22] Mohammad Alibakhshi-Kenari, Mohammad Naser-Moghadasi, Ramazan Ali Sadeghzadeh and Bal Singh Virdee and Ernesto Limiti, "New Compact Antenna Based on Simplified CRLH-TL for UWB Wireless Communication Systems," International Journal of RF and Microwave Computer-Aided Engineering, Volume 26, Issue 3, March 2016, pp. 217-225

[23] Mohammad Alibakhshi-Kenari and Mohammad NaserMoghadasi,"Novel UWB Miniaturized Integrated Antenna Based on CRLH Metamaterial Transmission Lines" AEUE Elsevier International Journal of Electronics and Communications, Volume 69 Issue 8, August 2015, Pages 1143-1149.

[24] A. Lai, C. Caloz, and T. Itoh, "Composite Right/Left-Handed Transmission Line Metamaterials,” IEEE Microwave., Mag., vol. 5, no. 3, pp. 34-50, Sept. 2004.

[25] C. J. Lee, M. Achour, and A. Gummalla, "Compact Metamaterial High Isolation MIMO Antenna Subsystem," in proc. Asia Pacifc Microwave Conference, pp. 1-4, 2008.

[26] Y. Li, Z. Zhang, J. Zheng and Z. Feng, "Compact heptaband reconfigurable loop antenna for mobile handset," IEEE Antennas and Wireless Propagation Letters, vol. 10, pp. 1162-1165, 2011.

[27] C. J. Lee, K. M. K. H. Leong, and T. Itoh, "Composite Right/LeftHanded Transmission Line Based Compact Resonant Antennas for RF Module Integration," IEEE Trans. Antennas and Propagation, vol. 54, no. 8, pp. 2283-2291, Aug. 2006. 